\title{
Margaret Atwood in the Second and Third Waves of Feminism on the Basis of Julia Kristeva's Theories
}

\author{
Sarieh Alaei ${ }^{a}$, Zahra Barfi ${ }^{\mathrm{b}}$ \\ Department of English Language and Literature, College of English, \\ Arak Branch, Islamic Azad University, Arak, Iran \\ a,bE-mail address: zohre.alaei@gmail.com , barfi.zahra64@gmail.com
}

\begin{abstract}
Although Margaret Atwood started writing in the second phase of feminism, some of her works show the features of the second and the third wave of feminism. It's clear in Atwood's Cat's Eye. Elaine, protagonist of the novel, and other female characters indicate these features. Some of Atwood's works imply Kristeva's theories. Unlike the second wave of feminism, Julia Kristeva as a postmodern feminist rejects the distinction between sex and gender believing that these two terms respectively represent biology and culture which cannot be separated from each other. This idea can be examined in Margaret Atwood's novel, Cat's Eye, as a feature of the third wave of feminism. The authors of this article seek to analyze Atwood's famous novel, Cat's Eye, in the second and third waves of feminism based on Julia Kristeva's theories.
\end{abstract}

Keywords: Margaret Atwood; Cat's Eye; Kristeva; second and third waves of feminism

\section{INTRODUCTION}

Atwood's Cat's Eye should not be regarded as a novel concentrating solely on the story of its fictional characters over the past years. The audience of this novel, becomes familiar with Canada's social and cultural events in the mid- twentieth century. It also enables the audience to look at the cultural elements of the course and feminist movements that took place at that time (Alaei 627). Among her novels, The Edible Woman or Lady Oracle and most of her poetry collections among which the famous Power Politics, also display overt feminist overtones (Azizmohammadi and Kohzadi 648). By ignoring the status of women in in the works of Margaret Atwood, it's hard to understand the importance of her literary works.

Most of the characters in her novels and short stories are female. She recreates women's subject in her writings and works. Margaret Atwood emphasizes on women's personality because she is completely aware of women. She believes that woman has no singular position. "A woman is the sum of the women". In her view, women merit in equality of right. Of course, it does not mean that women and men are the same. In her opinion, it's not so (Macpherson 22). Atwood began writing when women's awareness was developing. "Atwood's works was placed into a developing canon of contemporary women's literature and was viewed through the lens of the second wave feminist movement throughout the 1970s" (Rigney, qtd. in Macpherson 112). In the second wave of feminism, women's 
literature was paid attention more and in this literature, the writers talked about women. Then, Atwood's works were displayed with women conception and women's power.

Atwood's novels deal with the hidden subjugated world of women where injustice in society pushes them towards darkness. Margaret Atwood also depicts the internal urge of women to break all conventional identities in order to live with freedom. Margaret Also shows many examples where a victim in the novel adopts the path of survival and later enables her identity or self-free from any sort of conventional clutches where woman is seen as an object for sexual pleasure or for doing monotonous house hold works of washing clothes or sweeping floors (Upadhyay 30).

Atwood's novels talk about women who want to break conventional identities since they like to have freedom. Atwood depicts woman as an object for sexual pleasure or for doing house works. She is as a victim. In Atwood's novels, female characters involve in oppression in patriarchal society. They look for liberty, so they reject victim and oppression imposed them. These characteristics depict the second-wave of feminism. As noted, Atwood started writing when second-wave feminism emerged. (Upadhyay 30)

In 1990s, a critic called Eleonaro has stated that the works of Atwood should be seen and reviewed through postmodernist's view. With respect to postmodernism, Roa has discussed that Atwood has thought identity as a process not as a production and fixed entity. She has defined some conceptions such as unity and subjectivity (Macpherson 115).

Macpherson in her book has written Brooks Bouson, as a critic, "focuses on Atwood's use of feminism, though she focuses only on Atwood's first seven novels (the Edible Woman through to Cat's Eye)" (116).

Cat's Eye narrates a painter called Elaine Risely who lives in Vancouver. She has remarried and has two daughters. She comes back Toronto, where she has grown up, to prepare a painting exhibition for her works. In this trip, she remembers all her past. Most of her painting contain women's portrait- those familiar women in her childhood. One of the most central characters being effective on Elaine is Cordelia, her friend. With regard to the different views on Atwood's works in different decades, it seems necessary to ask some important questions; does this novel belong to the second wave of feminism or to the third wave of feminism?

\section{THE SECOND PHASE AND THE FALLING WOMEN}

Margaret Atwood has worked in 1960s and 1970s. Atwood's works are full of the second wave movement's signs. Some of the features of the second phase consist of forming women groups- requisiteness of abortion right and rejecting marriage. These features have been seen in Cat's Eye.

In the second wave of feminism movement, women revolted to have a special position for themselves. They recognized the root of their problem in patriarchal society. It's clear in chapter 11-falling women. "Falling Women" is an Elaine's painting. In this chapter, some women are been depicted who have fallen down. Those women have fallen because of men. In other words, men's thought about women made their falling. This falling indicates a kind of women's oppression. In one of the Elaine's paintings, there is no man, but it is about men. In this picture, some women are painted. In fact, in Elaine's idea, men cause them to fall. She describes the men as lightning and weather.

In chapter 11-falling women- Atwood writes about Susie. Susie involves in relation with Josef. He uses from Susie's body and at last, he leaves her alone while Susie is pregnant. 
After Susie does abortion, she hates Josef that he has done it with her: "He says he will never get over it, what he has done to Susie. This is how he thinks of it: something he's done, to Susie, to her inert and innocent flesh" (813).

In next part, Atwood depicts Cordelia's falling which finally she was in mental hospital. Cordelia was a beautiful and attractive girl and of course genius and talented but she could not make progress. It derives fear of her father. Her fear of father did not let her to identify herself and gain independency. Then in young hood, she fell down step by step.

In another section of novel, Atwood depicts Elaine and her falling next to Jon. In living with Jon, Elaine had severe difficulties and feels falling down: Elaine says: "Jon it's like failing downstairs" (933). It will be explained more in following parts.

In the second phase of feminism, according to radical feminists, real problem was studied in patriarchal society. In their words, every benefit belonged to men and culture defined everything in men's view. Then, women situate in low class. On the basis of radical feminists, every man was women's enemy and men used women in the direction of their goals. It caused to lose women's identity and there were some difficulties in women's life which was because of men's thought in this phase. On the whole, if male-oriented community did not look at women as a humble and low being and if they valued for women's identity, there would not be any falling women.

\section{THE SECOND PHASE AND APPEARANCE}

Elaine attends in a women group. They pose some questions basis on not wearing women dress and not wearing lipstick. They wear work boots and they don't shave their leg. One of the most crucial issues posed in the second decade was women's appearance. Radical feminists raised a question: why do women wear special clothes? Why do they make up? And some questions like these. They fired all of make-up equipment and some special clothes in the symbol of protest. The reason for this movement was sexual difference. They were going to reduce these differences. Then the women wore some men's work clothes and they prevented everything which showed them womanhood.

Another example for women's appearance in the second phase is obvious in Elaine. She says that she looks like a cabbage by wearing womanhood dresses. In this way, she mocks women dresses. Here, Elaine expresses her hate from special women's clothes. As explained, radical feminists protested for wearing woman clothes and they tried to wear men clothes like Elaine who wears pants instead of skirt. She does not like special clothes for women. Description of Elaine's mother's appearance illustrates the second wave of radical feminists: Elaine's mother wears slacks and manlike plaid shirt. Elaine's mother wears like men and prevents women's clothes. She never makes up. She belongs to the second wave of feminists.

\section{THE SECOND PHASE AND FORMATION OF WOMEN'S GROUPS}

In the second phase, women formed some special groups just for themselves. These groups were formed for increasing their awareness. In Cat's Eye, Atwood describes a special group which they made for themselves. Various women with different jobs attend in this group. Elaine, protagonist of the novel, goes in group. In her idea, there is a kind of attractive dirtiness and it is unusual. 
In these groups, they talk about patriarchal society by anger and harshness. They talk about how male-oriented society behaves them as slave? They believe that anger and coarseness is vital for a revolt. What they discuss is based on their oppression. These women describe patriarchal society and in this way, they conclude that there is tyranny toward them. They are oppressed. As Kate Millet has expressed in sexual politics, she has descried and introduced male community. She has manifested that everything is in the control of maleoriented society and it dates back western thought. Although, she believes that it is vital to revolt and fight against. Elaine depicts feminist thought about their oppression. She says that in their patriarchal society, women have been raped and their art has been ridiculed.

In another example, Elaine describes Cordelia's home. In their home, dinner is different in father's presence. When the father is not at home, things are slapdash. They jump up from the table and everything is forgotten but when he is at home, everything is neat. There are flowers on the table and nothing is forgotten. It indicates that everything is in the control of men.

\section{THE SECOND PHASE AND THE RIGHT OF ABORTION}

Another critical issue posed in this decade was freedom in abortion. There was a main question among radical feminists: should women live with men or they can live separately? This discussion led to another debate posed as "free abortion". It means that women should access to abortion freely. Radical feminists, in this decade, wanted to have liberty by means of abortion. In this way, they believed that they have had control on their bodies. Elaine says: "Women like me, with a husband, a child, have been referred to with some scorn as nukes, for nuclear family. Pronatalist is suddenly a bad word" (871)

On the other hand, second wave of feminists thought that they could make progress and gain their purposes just by cutting their relation with men. In fact, they called for autonomy. It's clear in Cat's Eye, in women's groups, the women express:" That way you've paid your dues. If you stay with the man, whatever problems you are having are your own fault" (871)

Or in chapter ten, when Elaine talks about Josef and Jon, she says: "I don't want to marry Josef, or anyone else. I have come to think of marriage as dishonorable, a crass tradeoff rather than a free gift" (756) Like the second wave of feminists, she has no positive and good idea about marriage. It means that marriage and bearing the child are rejected.

\section{THE SECOND PHASE AND SEPARATION OF SEX AND GENDER IN WOMEN'S OPPRESSION}

The second wave feminists believed that the women were oppressed. Male-oriented society has oppressed them and it's necessary to revolt against them. The root of this idea can be discussed in the light of separation of sex and gender. They believed that there is a distinction between sex and gender (Rampton 1).

A patriarchal society creates and defines gender. It means that community culture defines womanhood. It is not biological. In as much as male-oriented society had no positive view toward woman and contemns her, woman's gender is in a low value and that made woman's oppression (Millett ix).

In the second wave, women argued on women's oppression. They posed some questions; why and how women were oppressed? Male-oriented society had restricted women 
to their body. From their point of view, women were created just for house works and sexual pleasure. In the second wave, feminists expressed that these thought of patriarchal society caused women's oppression. Postmodern culture is a highly self-conscious culture which through its denial of the Enlightenment and modernity has brought about a maddening obsession with self-related topics (Mahmoudi, Azizmohammadi and Kohzadi 633). Most of Atwood's novels depict the women oppressed in dominated culture while they look for their identity and freedom (Upadhyay 30).

This quality can be seen in Cat's Eye. For instance, in Susie and Josef relationship, it can be expressed that Josef wants Susie just for sexual pleasure not for marriage and forming family. As soon as Josef impregnates Susie, he leaves her immediately. It is clear that if Josef does not restrict Susie to her body, he will not leave her and will not make her oppression at all. This quality is opposed to the idea that "human being as a rational and emotional being has always involved in the process of falling in love and lovemaking. This does not end to sensual and sexual relationship between two genders, but human being needs others for communication and removing the sense of loneliness" (Kohzadi and Azizmohammadi 665).

\section{THE SECOND PHASE AND CYCLICAL TIME}

One of the important issues posed in the late of second generation of feminism movement was cyclical time. As stated in "Women's Time", Julia Kristeva has noted that unlike first generation, the second generation of feminists came back to cyclical time. In Julia Kristeva's view: "father's time refers to linear time that men have inhabited, with its sense of history, destiny, and progress. Mother's species refers to cyclical time which evokes the realm that women have traditionally occupied: a space that generates the human species, a space like the Chora, where time is marked by repetition on the one hand and a sense of the eternity of the species on the other" (Kristeva, qtd. in MacAfee 2004 94). Then, cyclical time refers to repetitious conceptions.

In Cat's Eye, when Elaine says: "Jon, for instance, would call this illustration. Any picture that's a picture of something recognizable is illustration, as far as he's concerned. There is no spontaneous energy in this kind of work, he would say" (827).It indicates that Elian's paintings points to cyclical time. Her painting is illustration. It means that she paints usual and daily conceptions and there is no creativity and invention in her works. This refers to cyclical time which is the characteristic of the second generation of feminism movement.

\section{THE THIRD WAVE OF FEMINISM AND NO DISTINCTION BETWEEN SEX AND GENDER}

Unlike the second wave, the third wave of feminism which exposes postmodern characteristic, does not concern distinction between sex and gender. Julia Kristeva, as a member of postmodern society, has not believed to distinction between these conceptions. She has proved it in "motherhood". In "motherhood" model, the being can be both producer of species and producer of culture. Kristeva states that sex which shows biological body and gender which show culture are not separate. One of the reasons to oppose with marriage and bearing the child, in the second wave, is to believe distinction between sex and gender. Patriarchal society limited the women to their body (sex) and the women feminists opposed with this opinion to achieve liberty and control on their body. Then, they rejected marriage 
and bearing the child. While, the third wave of feminist criticize and explicitly state that there is no distinction between biological sex and cultural gender. As a result, there is no barrier in marriage. In Cat's Eye, Elaine marries and has a child contrary to other women (John as her husband and Sara as her daughter). It indicates that Elaine lives in the second wave of feminism movement but she belongs to the third wave.

\section{THE THIRD WAVE OF FEMINISM AND JULIA KRISTEVA IN THE SEMIOTIC AND SYMBOLIC MODE}

Kristeva, as a member of postmodern community, believes that we should accept the differences of the semiotic and the symbolic mode and put these modes in parallel. As noted, Kristeva has not separated sex and gender. It means that, in her view, two modes of semiotic and symbolic of signification should be next and in parallel. Otherwise, it will be followed by mental problems. In each being, these two modes should be next in balance or else it's impossible to gain calmness. This matter can be applied in couple relationship. If a man and a woman have a correct knowledge from two modes of semiotic and symbolic, they can live without struggle and strife. On the other hand, if they, couple, do not have the same viewpoint on this matter, it will long to strife. Man and woman should be aware of this matter which sex and gender are not independent. It means that biology of the being and its cultural role can't be distinguished. Both of them are vital to live a calm and safe life.

That, in last waves of feminism movement, the women were limited to their body caused mental problems and it made women's revolt against male-oriented community. This revolt had no good consequence and led to banish and rejection of marriage and bearing the child. Whereas it would not take place if they were aware of this matter and complete awareness of two modes inside the being (semiotic and symbolic).It is seen obviously in postmodernist's view.

As explained, according to Kristeva, distinction of sex and gender is impossible. In postmodern viewpoint, one dimension being has no meaning. There is no being which is limited just to one of two dimensions since it will be followed by mental problems. That's why the third of feminism movement has a positive view toward marriage and bearing the child and values it. They believe that couple can live without any strife next to each other of course in the light of their complete awareness in human being dimensions. As is clear in Cat's Eye, Elaine says about her second marriage. In her view, Ben conceives her well. He can understand her artistic spirit and he helps her every time especially at home and in vital situations.

It implies that Elaine and Ben have a complete conscious in human being dimension, in two modes semiotic and symbolic. It can't be applied for the first Elian's marriage. Elaine and Jon are not aware of this matter. They do not have deep and correct awareness about the semiotic mode and the symbolic mode and they cannot stay next each other and divorce. In living with Jon, Elaine feels falling. Jon never accepts Elaine and never values for her works. In Jon's idea, Elian's painting just is illustration. Jon wants Elaine just for sexual pleasure. After some years, Jon communicates and has relation with another woman. He does not care to his house and Elaine. He has no exact awareness of women and sees her limited to the body. That's why he cannot communicate with Elaine very well. Such as the second wave feminists, Elaine follows to revolt. She wants to improve her works but it is impossible next to Jon. Then, she chooses to divorce. 
In living with Ben, Elaine and he have an accurate awareness about sex and gender and two dimensions inside human being. They reach to this point that sex and gender cannot be distinguished from one another and the women need not be restricted by their bodies and they should be looked in different eyes. Then, they can live comfortably. Later, Elaine understands that the problem in living with Jon had hidden in this point! "We are silent, considering shortfalls. There's not much time left, for us to become what we once intended" (672). And "If you hadn't been so crazy," I say, "it could have worked out. With us, I mean" (678)

These imply that they accept their fault based on incorrect awareness about themselves. This matter is completely reverse about marrying with Ben. Elaine and Ben can live very well without any struggle. As explained, the reason behind is that they profoundly recognize and realize themselves.

\section{THE THIRD WAVE OF FEMINISM AND FOLDING OF NATURE AND CULTURE IN KRISTEVA'S MOTHERHOOD}

Julia Kristeva has proved that nature and culture are folded together by maternal body. "The function of motherhood depicted here is radical: to be a fold between nature and culture, self and other, life and death, a fold that is a catastrophe of being that shatters the usual representations. I read "catastrophe" here as meaning not an end or cataclysm but "an event that produces a subversion of the usual order of things" (MacAfee 87). And

Clearly there is a fold in Kristeva's work between culture and bodies, what others might call gender and sex. In some essays it is the maternal body. But in many others it is simply the speaking being, a person who happens to have been born into a network of relationships, kin, language, and law, who must negotiate these as well as the knowledge of her or his own coming death. So this speaking being has many passages to negotiate, and is a fold in them all (89).

According to essentialist, body and mind are separate and the women are attributed to their body as well as last waves of feminism movement. In postmodern time, Kristevahas criticized this idea and has proved this is not so. She has claimed it through motherhood and maternal body.

She hasn't distinguished between body and culture but she has claimed that they are in a process and they are fold together. In this way, Kristeva wants to prove contemporary women attributed to the linear time and cyclical time, wants both to experience motherhood and to participate in social, cultural and political activities. Kristeva has indicated this matter by analyzing motherhood and maternal body. This matter can be applied in contemporary time and also it is seen in Atwood's Cat's Eye. Married life of Elaine shows this matter very well. She has a husband and child and she has improved in her work: "I have a husband, not my first, whose name is Ben. I also have two daughters, by now grown up. My career is why I'm here, on this futon, under this duvet. I'm having a retrospective" (48)

It shows that Elaine behaves like a member of postmodern society. Marriage- having the child and progress in her work as a painter. She believes that the woman is not limited to her body and the women not only are mother but also are guarantor of culture durability. All of these discussions imply that body and mind are not distinguished. Margaret Atwood is aware of this matter and she does not know the women limited to body, as well as Kristeva. 


\section{THE THIRD WAVE OF FEMINISM AND SEX AND GENDER RELATIONSHIP IN CORDELIA'S RELATION WITH HER FATHER}

In cat's Eye, As Elaine describes Cordelia's relation with her father; it does not seem a good relation. Cordelia fears of her father, she fears that she does something or talk about something which is not her father's favorite: "She's too frightened of him. She's frightened of not pleasing him. And yet he is not pleased. I've seen it many times, her dithering, fumblefooted efforts to appease him. But nothing she can do or say will ever be enough, because she is somehow the wrong person" (639).

This relation is the symbol of the second wave of feminism. In the second phase which feminist believed in distinction of sex and gender, they stated that patriarchal society made gender. That, women should behave in a special manner is determined by patriarchal society. That, Cordelia, as a woman, can't communicate with her father refers to this matter. There are barrier between them and that is distinction between sex and gender leading to Cordelia's oppression. On the other hand, Elaine communicates with Cordelia's father very comfortably. They speak, discuss. In Cordelia's home, Elaine and Cordelia's father speak about atom. In Elaine's idea, he wants this: give and take, talking with each other. It implies that Elaine belongs to the third phase of feminists and postmodern time.

Elaine has explicitly accepts and understands these conceptions. If someone distinguishes them, she will be convicted to oppression which patriarchal society imposes her. On the other hand, when someone does not distinguish them, not only she won't be oppressed but she will be an independent and free being. This person believes in process philosophy. In postmodern time, all of conceptions are based on this "process" philosophy.

Process philosophy is not a system of philosophy; it has no strict tenets; rather, the term captures a style of metaphysical inquiry that emphasizes events rather than substance. Standard metaphysics emphasizes substance, essence, fixity, persistence, identity, and continuity. It seeks the essence that can survive the comings and goings of accidents: what persists through time. Process metaphysics emphasizes change, event, novelty, activity, and fluidity (MacAfee 87).

Then, everything is based on change and activity and there is no place for fixity and stability. On the basis of Kristeva and her theory, conceptions "gender" and "sex" are in this process. They are fold. In Kristeva's view, subjectivity is not fixed but it is in process, it means it is in an open system (Kristeva, qtd. in Macafee 41). As a result, subjectivity and identity are not fixed conceptions. They are in a process. They are always in a change.

As explained in last parts, according to Kristeva, nature and culture are folded in maternal body. It means that they are not stable and distinct entities, they situate in a process. Other critics called them gender and sex. Then, sex and gender are in a process as well. Whereas, Elaine is informed of this process philosophy she does not observe any oppression. She looks at human being in a more various way than Cordelia. That's why she can communicate with Cordelia's father well.

\section{CONCLUSION}

While the third wave feminists do not believe in separation of sex and gender. They study them next to each other. The second wave feminist was not successful because they studied sex and gender in a completely different manner. The second and important conclusion taken is that "Cat's Eye" which is written in 1988 belongs to the third wave of 
feminist while it has characteristics of the second wave, as well. Margaret Atwood started writing in the rise of the second-wave feminism movement. Maybe, that's why most of her novels play a tune of the second wave.

\section{References}

[1] Alaei Sarieh, Fatemeh Azizmohammadi, Hamedreza Kohzadi, Anthropologist 17(2) (2014) 627-631.

[2] Atwood Margaret, Cat's Eye. New York: A Division of Random House, INC, 1988.

[3] Azizmohammadi Fatemeh, Hamedreza Kohzadi, Anthropologist 17(2) (2014) 647-653.

[4] Kohzadi Hamedreza, Fatemeh Azizmohammadi, Anthropologist 17(2) (2014) 655-667.

[5] Macpherson Heidi Slettedahl, The Cambridge Introduction to Margaret Atwood. Cambridge University Press, 2010.

[6] Mahmoudi Elham, Fatemeh Azizmohammadi, Hamedreza Kohzadi, Anthropologist 17(2) (2014) 633-638.

[7] McAfee Noelle, New York and London: Routledge (2004) 75-90.

[8] Millett Kate, 1969 (2000). Sexual Politics. University of Chicago Press. pp. ix-x.

[9] Rampton, Martha, The Magazine of Pacific University 41(2) (2008) 1.

[10] Upadhyay Mukti, International Journal of recent Research and Review (2012) 27-30. 